\title{
DESAFIOS DA FORMAÇÃO DOCENTE DE EDUCADORES/AS DE JOVENS E ADULTOS - UMM ESTUDO DE CASO
}

\author{
THE CHALLENGES OF TEACHING TRAINING OF ADULT EDUCATORS - A CASE \\ STUDY
}

\author{
M. F. SILVA ${ }^{1, *}$ \\ ${ }^{1}$ Universidade do Estado de Minas Gerais, Programa de Pós-Graduação em Educação, Brasil
}

\section{ARTICLE INFO}

Article history:

Received 2018-07-01

Accepted 2018-12-20

Available online 2018-12-21

*Autor correspondente:

E-mail:mfsneo@gmail.com
Palavras-chave: Formação Docente. Educação de Jovens e Adultos. Educadores/as de Jovens e Adultos

Keywords: Teacher Training. Adult Education. Adult Educators.

RESUMO. Este estudo apresenta os resultados de uma pesquisa realizada no Programa de Pós-Graduação em Educação da Universidade do Estado de Minas Gerais (UEMG), cujo objetivo foi a reflexão dos desafios colocados na formação de educadores/as de jovens e adultos. Objetivou-se a compreensão de questões relacionadas aos limites e às contribuições da experiência formativa de um projeto de extensão da Universidade Federal de Minas Gerais (UFMG), denominado PROEF-2, dedicado à iniciação à docência de graduandos/as em licenciatura em turmas de Educação de Jovens e Adultos (EJA). O PROEF-2 abarca dimensões formativas que envolvem a interdisciplinaridade universitária, estabelecendo objetividade na produção e no desenvolvimento de alternativas para projetos pedagógicos de aprendizagem na modalidade EJA e na formação inicial de professores/as. Nesse sentido, esta pesquisa utilizou-se de uma abordagem qualitativa, que optou pelo uso do estudo de caso, como método investigativo, pela observação participante das reuniões formativas do PROEF-2 e pela entrevista semiestruturada com coordenadores e com monitores do projeto, como instrumentos de coletas de dados. Os resultados indicam que o PROEF-2 contribui para a constituição de um espaço de formação de professores/as, com especificidades formativas voltadas para a EJA, contribuindo efetivamente para a formação de educadores/as de jovens e adultos. Suas limitações encontram-se nas delimitações institucionais inerentes a um projeto de extensão. Entende-se, no entanto, que as contribuições superam as limitações e que estas podem ser superadas com planejamentos futuros, adequados às demandas da formação docente na EJA.

ABSTRACT. This study presents the results of a research carried out in the Pos-Graduate Program in Education of the State University of Minas Gerais (UEMG), whose objective was the reflection of the challenges posed in the training of adult educators. The objective was to understand questions related to the limits and contributions of the training experience of an extension project of the Federal University of Minas Gerais (UFMG), called PROEF-2, dedicated to teaching undergraduates courses students in Adult Education classes. The PROEF-2 encompasses formative dimensions that involve university interdisciplinarity, establishing objectivity in the production and development of alternatives for adult education pedagogical learning projects and initial teacher training. This research used a qualitative approach, which chose to use the case study, as an investigative method, through the participant observation of the PROEF-2 formative meetings and the semistructured interview with coordinators and project monitors, as instruments of data collection. The results indicate that PROEF2 contributes to the creation of a space for the training of teachers, with formative specificities focused on Adult Education, effectively contributing to the formation of educators of adults. Its limitations lie in the institutional delimitations inherent in an extension project. It is understood, however, that the contributions overcome the limitations and that these can be overcome with future planning, adequate to the demands of the teacher training in the Adult Education. 


\section{Introdução}

A EJA, como modalidade de ensino, carece de propostas formativas que definam e orientem uma formação específica de professores/as para atuação nessa modalidade educacional. Faz-se necessária, então, uma argumentação em favor de uma política de formação de educadores que considere os contextos históricos dos estudantes jovens e adultos, perfazendo os contornos formativos que a EJA tanto reivindica (BORGHI, 2007). Nesse contexto, Soares (2008) expõe que a formação docente do educador de jovens e adultos não é um tema necessariamente novo, mas, somente nas últimas décadas, ganhou dimensão mais ampla. Os avanços constitucionais recentes e a contínua luta dos movimentos sociais certamente favoreceram a oferta de ensino para o público jovem e adulto. No entanto, a relevância destinada à EJA e, consequentemente, a formação docente na Educação de Jovens e Adultos no cenário educacional ainda permanecem aquém da real necessidade.

Seguindo essa linha argumentativa, Ribas e Soares (2012) consideram primordial a busca por uma formação docente inovadora para com o educador de jovens e adultos. Almeja-se, nesse sentido, a uma formação compromissada com a formação humana dos indivíduos, visto que os educadores/as de jovens e adultos lidam com pessoas que ficaram à margem dos processos de escolarização, indivíduos, muitas vezes, ausentes de experiências escolares de cunho humano. Obstina-se, assim, uma formação que não se limite simplesmente a transmissão de conhecimentos, mas que igualmente propicie reflexão crítica e emancipação cidadã.

Esse não é um pensamento recente nos diálogos e referências acerca da EJA. Desde o final da década de 1950, as considerações do educador Paulo Freire (1963; 1967; 1970 ; 1996) sobre a teoria e a prática de uma educação transformadora, especialmente na Educação de Jovens e Adultos, vêm inspirando e orientando o campo educacional ao redor do mundo. Paulo Freire propunha uma educação libertadora e humanizada, direcionada para uma sociedade que sente, ouve e pensa. Uma proposta que representa a interdisciplinaridade, a construção do conhecimento por meio da articulação dos saberes e das vivências individuais e coletivas dos sujeitos alunos. O educador de adultos, nesse contexto, reconhece e valoriza os estudantes jovens e adultos como seres de identidade histórica e cultural (MIRANDA; BARROSO, 2007). Passadas quase seis décadas, o pensamento de Freire mostra-se contemporâneo e inovador e, em certa medida, cabe à sociedade brasileira reflexão crítica por não ter plenamente implantado, em nosso sistema educacional, a forma de compreensão de mundo e de pessoas aludida por Paulo Freire. 
Nesse sentido, indicadores apontam que a temática da formação de professores/as para a Educação de Jovens e Adultos apresenta desajuste com as efetivas demandas do campo de estudos da EJA. Apesar de relevantes e do gradual aumento das pesquisas científico-acadêmicas referentes a essa temática, os estudos a respeito da formação docente para a EJA ainda são insuficientes (SOARES, 2003). Constata-se, então, que, no campo das pesquisas e dos estudos em EJA, existe grande demanda por pesquisas relativas à formação específica do educador de jovens e adultos. Sendo assim, a pesquisa proposta, neste estudo, justifica-se pela intrínseca necessidade de averiguações a respeito dos desafios inerentes à formação docente na EJA.

Dessa forma, este estudo tem como objeto de pesquisa a investigação e a compreensão das questões relacionadas aos limites e às contribuições da experiência formativa do Projeto de Ensino Fundamental de Jovens e Adultos do $2^{\circ}$ Segmento ${ }^{1}$ para a formação de educadores/as de jovens e adultos, bem como a reflexão acerca dos conceitos, das metodologias e dos desafios colocados no contexto dessa formação. O PROEF-2 é um projeto de extensão que integra um amplo Programa de Educação Básica de Jovens e Adultos $^{2}$ da Universidade Federal de Minas Gerais ${ }^{3}$. O Programa é composto pelo Projeto de Ensino Fundamental de Jovens e Adultos do 1을 Segmento (PROEF-1), pelo PROEF-2 e pelo Projeto de Ensino Médio de Jovens e Adultos (PEMJA). O PROEF-2 é desenvolvido nas dependências do Centro Pedagógico (CP), a escola de Ensino Fundamental da UFMG, e oferece aos funcionários da universidade e à comunidade externa em geral a oportunidade de escolarização na modalidade EJA.

Entende-se que a problemática apresentada, relacionada à formação docente na Educação de Jovens e Adultos, possui relevância e precisão investigativa perante o campo da educação de pessoas jovens e adultas. Nesse sentido, esta pesquisa utilizou-se de uma abordagem qualitativa, que optou pelo uso do estudo de caso, como método investigativo, e pela observação participante e pela entrevista semiestruturada, como instrumentos de coletas de dados. A observação participante ocorreu nas reuniões formativas do PROEF-2 e as entrevistas semiestruturadas foram realizadas com coordenadores e com monitores do projeto.

\section{Contextualização do Campo de Pesquisa: O PROEF-2}

A pesquisa aqui apresentada teve como sujeitos do processo investigativo: coordenadoras e professores/monitores do PROEF-2. A história esse projeto tem início no ano de 1986, quando era conhecido como Projeto Supletivo do Centro Pedagógico da

${ }^{1}$ Doravante PROEF-2.

Este Programa está vinculado à Pró-Reitoria de Extensão da UFMG e ao NEJA - Núcleo de Educação de Jovens e Adultos da Faculdade de Educação - FaE/UFMG.

${ }^{3}$ Doravante UFMG. 
UFMG. O Projeto Supletivo foi criado em meio a mudanças institucionais na universidade e após reivindicações de funcionários da instituição, que não possuíam escolaridade e/ou tinham escolaridade incompleta. Por intermédio das reivindicações desses funcionários e da ação institucional da Reitoria e Pró-Reitoria de Extensão da UFMG, foi criado o Projeto Supletivo, que ofertava turmas de alfabetização e de ensino supletivo no espaço físico do CP/UFMG, em horário noturno (DINIZ-PEREIRA et al., 2008). Assim foi até o ano de 1998, quando ocorreu a segmentação do Projeto Supletivo em três projetos de alfabetização e de escolarização na modalidade EJA ${ }^{4}$. O primeiro correspondia aos anos iniciais do Ensino Fundamental, o segundo aos anos finais do Ensino Fundamental e o terceiro ao Ensino Médio.

Atualmente, a proposta do PROEF-2 dispõe pela conclusão do Ensino Fundamental 2 em três anos de curso. As turmas são denominadas iniciantes, continuidade e concluintes e representam estágios subsequentes de aprendizagem. A quantidade de turmas referentes a cada estágio pode variar conforme a quantidade de alunos aptos a avançar de uma fase de ensino para outra, sendo geralmente duas turmas para cada estágio de aprendizagem. A forma de ingresso ocorre através de processo seletivo que avalia habilidades como escrita, leitura e resoluções aritméticas. A seleção é feita para ingresso somente nas turmas iniciantes, não sendo possível o ingresso imediato em turmas de continuidade ou de concluintes. Essa foi uma decisão pedagógica do projeto, visando a uma experiência escolar completa por parte dos estudantes. Aos concluintes do PROEF-1 é garantida a inserção imediata ao PROEF-2, e consequentemente no PEMJA, caso seja de interesse dos alunos (SILVA, 2011).

Todos os professores/monitores do projeto são estudantes dos diversos cursos de licenciatura da UFMG $^{5}$ e bolsistas da Pró-Reitoria de Extensão ${ }^{6}$. Eles desempenham 20 horas semanais de trabalho, entre reuniões formativas, preparação e execução de aulas. A seleção dos bolsistas é feita anualmente, mediante edital público de seleção, sendo possível a permanência no projeto como bolsista pelo período de dois anos ${ }^{7}$. O PROEF-2 dispõe de 24 bolsas de extensão, organizadas em 20 bolsas destinadas especificamente a estudantes de licenciaturas e 04 bolsas de caráter administrativo que podem ser preenchidas por estudantes de outras áreas. Por tratar-se de um projeto de iniciação à docência, não é exigida dos professores/monitores experiência pregressa em docência ou conhecimentos em EJA.

${ }^{4}$ PROEF-1, PROEF-2 e PEMJA, respectivamente.

${ }^{5}$ A saber: Artes ou Educação Física, Biologia, Geografia, História, Língua Estrangeira (Inglês ou Espanhol), Língua Portuguesa e Matemática.

${ }^{6}$ No início do projeto, ainda na década de 1980, os bolsistas eram voluntários. Atualmente, recebem Bolsa Institucional no valor de $\mathrm{R} \$ 400,00$ por mês.

${ }^{7}$ O período de permanência no PROEF-2 como bolsista de extensão não é definido pela Pró-Reitoria de Extensão, mas sim pela coordenação do projeto. Em casos excepcionais, como ausência de novos candidatos, esse período pode ser estendido. 


\subsection{A Concepção Formativa do PROEF-2}

O PROEF-2 dispõe de uma concepção formativa direcionada ao campo da formação docente na educação de jovens e adultos. São ofertadas turmas do ensino fundamental 2 , na modalidade EJA, cujos professores são alunos de licenciatura da UFMG. Esses professores são coordenados e orientados por professores efetivos do Centro Pedagógico (CP/UFMG). No sentido de orientar as ações pedagógicas e didáticas das turmas que fazem parte do projeto, o PROEF-2 dispõe de três reuniões semanais de caráter formativo. Essas reuniões são divididas da seguinte forma:

- Reunião formativa com os professores/monitores da mesma área de conhecimento: tem como principal função a orientação das pautas curriculares específicas de cada disciplina. Essa reunião é geralmente coordenada por um docente de igual formação dos monitores professores e ocorre semanalmente;

- Reunião formativa com todos os professores/monitores de uma mesma turma de ensino, independente da área de conhecimento: tem como principal função a orientação e a resolução de problemas comuns ao cotidiano escolar e também ocorre semanalmente;

- Reunião formativa com todos os monitores/professores do projeto, juntamente com coordenadores e alguns alunos representantes das turmas do PROEF-2: denominada como reunião geral, ocorre mensalmente e tem como principal função o diálogo entre os integrantes do projeto, sejam eles coordenadores, professores/monitores ou alunos. Um fator relevante dessa reunião é a abordagem de temas relativos ao campo de pesquisa da educação de jovens e adultos ${ }^{8}$, no sentido de debater acerca da atualidade de conceitos e de propostas do da EJA.

Fica evidente o viés de formação docente presente no PROEF-2, enquanto projeto de extensão dedicado à iniciação docente na modalidade EJA. As referidas reuniões formativas envolvem coordenação, orientação e diálogo, no sentido de fortalecer a prática docente nas turmas de Educação de Jovens e Adultos ofertadas no projeto. Trata-se uma experiência docente formativa que se desenvolve no âmbito de uma instituição de ensino superior e que vincula sua atividade prática à educação básica.

O PROEF-2 conta com três equipes de trabalho, referentes aos níveis de ensino em curso no projeto. São elas: Equipe de Iniciantes, destinada aos alunos que iniciam os estudos no projeto; Equipe de Continuidade, destinada aos alunos em continuidade no projeto, ou seja, aprovados ao passar pela Equipe de Iniciantes; e Equipe de Concluintes, destinada aos alunos em fase final de estudos no projeto. O número total de turmas e de alunos no projeto pode variar conforme fatores relacionados à procura por vagas e à evasão escolar. 
Com relação ao grupo pesquisado, foi escolhida uma equipe de trabalho do PROEF2 para observação participante e realização de entrevistas. A equipe escolhida foi a Equipe de Concluintes, que trabalha com alunos em fase final de estudos no PROEF-2. A equipe é composta por sete monitores professores, estudantes dos cursos de graduação da UFMG, e que são orientados por uma professora efetiva do CP/UFMG. Os monitores professores da referida equipe lecionam para duas turmas, intituladas de Turma 78 e Turma $79^{9}$, em um total de três aulas diárias, de segunda à quinta, em horário noturno.

A escolha da Equipe de Concluintes, como grupo pesquisado, ocorreu de forma aleatória, uma vez que a distribuição de monitores bolsistas no projeto transcorre de forma equitativa, sempre mesclando bolsistas veteranos com bolsistas novatos. Nesse contexto, observou-se apenas a disponibilidade de horários para realização das observações participantes e das entrevistas semiestruturadas, assim como a predisposição dos participantes da pesquisa para com os objetivos desta investigação.

\section{Análise e Interpretação dos Dados de Pesquisa}

As reuniões formativas, também denominadas de reuniões de equipe, ocorrem todas as sextas-feiras e possuem direcionamento pedagógico e reflexivo acerca da prática docente dos monitores professores. Trata-se de reuniões obrigatórias para os monitores professores bolsistas, no intuito de explorar e de compartilhar as experiências em sala de aula. Nessas reuniões, são apresentados planos de aula, expostas divergências ou dúvidas sobre a prática docente e realizadas orientações formativas que visam ao desenvolvimento das atividades escolares. Foram observadas quatro reuniões de equipe e uma reunião geral.

A observação participante das reuniões formativas do PROEF-2 evidenciou a dimensão formativa e institucional do projeto, no sentido de iniciar estudantes de licenciaturas na prática docente. Para além dessa iniciação à docência, cabe ressaltar a possibilidade real de formação inicial de educadores de jovens e adultos propiciada pelo espaço de formação docente do PROEF-2. Por mais que as reuniões formativas do projeto assemelhem-se com conselhos de classe, elas oferecem arcabouço teórico e prático para o enfrentamento de futuros desafios da profissão docente, especialmente na modalidade EJA.

Nesse contexto, é preciso relativizar a amplitude desse espaço formador, assim como refletir acerca das possibilidades de formação de professores na Educação de Jovens e Adultos. Sabe-se que a formação do profissional docente atuante na Educação de Jovens e Adultos almeja por metodologias e práticas inovadoras, mas, igualmente, entende-se que

${ }^{9} \mathrm{O}$ número das turmas é definido no ingresso no PROEF-2, ainda na fase iniciante, e permanece o mesmo até a fase final de estudos. 
os processos formativos na EJA devem proporcionar a realidade cotidiana da profissão docente no ambiente escolar.

Com o objetivo de aprofundar a investigação acerca da formação docente no PROEF-2, foram realizadas entrevistas semiestruturadas com os integrantes da equipe observada. A definição da amostra dos sujeitos de pesquisa foi configurada a partir das conjunturas e dimensões do projeto $^{10}$ de extensão. Para tanto, foi elaborado um roteiro de entrevistas previamente elaborado, que buscou a análise e o entendimento da proposta formativa profissional apresentada no PROEF-2.

Os monitores entrevistados demonstraram valorização e reconhecimento pelo processo formativo docente em curso no PROEF-2. Entretanto, não se verificou uma reflexão crítica mais aprofundada acerca da necessidade de processos de formação profissional na Educação de Jovens e Adultos como o por eles vivenciado. Isso pode ser avaliado como algo natural, em meio à diversidade de pensamentos e de percursos formativas. Todavia, independente das representações que cada monitor professor objetivou do processo formativo docente em questão, pôde-se positivamente constatar a experiência formativa profissional docente por eles experimentada no PROEF-2.

As entrevistas com as coordenadoras do PROEF-2 demonstraram a qualificação de quem está à frente da coordenação e da orientação docente dos monitores professores. Nesse sentido, o PROEF-2 apresenta uma linha de aprendizado profissional construído a partir da própria profissão docente, de professores para professores em formação. Verificase o que Nóvoa (2007) define como a necessidade de uma formação de professores que se desenvolva dentro da profissão, baseando-se na aquisição de uma cultura profissional e concedendo aos professores mais experientes um papel central na formação dos mais jovens. Trata-se de um momento muito sensível à formação de professores/as, o momento da indução profissional, no qual os docentes em formação se integram à cultura profissional por meio de exemplos, de condutas e de ensinamentos do professorado com maior experiência.

\subsection{Os Limites e as Contribuições da Experiência Docente no PROEF-2 para a}

\section{Formação de Educadores/as de Jovens e Adultos}

A análise das atividades formativas do PROEF-2 priorizou a apreciação do projeto enquanto espaço de desenvolvimento da prática docente para professores em formação. Nessa perspectiva, avalia-se que a maior contribuição do PROEF-2 para com o campo da EJA está na possibilidade efetiva de formação profissional docente de educadores/as de jovens e adultos. Diante de uma modalidade educacional carente de propostas de formação

\footnotetext{
${ }^{10} \mathrm{O}$ projeto dispõe de 03 equipes de trabalho, relacionadas às 03 fases de ensino do PROEF-2: Iniciantes, Continuidade e Concluintes. Uma vez que todas as equipes dispõem da mesma rotina de trabalho, optou-se, aleatoriamente, pela investigação e análise dos trabalhos da Equipe de Concluintes.
} 
inicial de professores/as como é a EJA, o PROEF-2 surge como um espaço repleto de práticas e de instrumentos de formação que proporcionam uma vivência docente em conformidade com a cultura profissional da EJA. Evidencia-se, assim, uma dimensão formativa voltada para a descoberta de conhecimentos e de saberes a partir do exercício da prática profissional. Nesse sentido, Tardif (2002) explica a importância de movimentos de inserção à cultura da profissão docente, no intuito de provocar o surgimento de novos atores políticos situados na interface entre a formação e a profissão.

Considerando as possibilidades de aprendizado nas práticas formativas disponibilizadas no projeto, entende-se que outra vertente de contribuição para a formação docente presente no PROEF-2 seja a análise reflexiva sobre realidades da prática profissional docente. Dessa forma, os monitores professores têm a possibilidade de contrastar e de refletir sobre as divergências e os paradoxos existentes entre a formação teórica dos cursos de licenciatura dos quais fazem parte e a experiência docente vivenciada no projeto. Essa é uma discussão complexa e que, como bem esclarece Ventura (2015), envolve a formação de professores para a educação básica de forma geral, uma vez que os desafios da atividade docente cotidiana ocupam lugar secundário nos cursos de licenciatura. No caso específico da modalidade EJA, raramente, os cursos de formação de professores refletem o fazer pedagógico contextualizado com a realidade dos jovens e adultos. A formação essencialmente disciplinar dos cursos de formação de professores revela questões relacionadas ao distanciamento entre teoria e prática que, para o bem maior de uma formação em conformidades com as realidades da atividade docente, precisam ser superadas. Sendo assim, o PROEF-2 contribui para a formação de um profissional docente questionador acerca das concepções e das vertentes teóricas de sua própria formação.

Ao dissertar sobre a especificidade na formação de educadores de jovens e adultos, Soares (2015) define especificidade como algo que constitua qualidade, em convergência com aspectos de peculiaridade e de ação própria. Observando as particularidades do PROEF-2, por meio de sua concepção pedagógica para com o ensino destinado ao público da EJA e/ou pela proposta de formação docente vigente no projeto, observa-se uma configuração congruente com as caracterizações de uma formação específica na educação de pessoas jovens e adultas. Os monitores professores vivenciam uma atividade escolar dialógica, que valoriza e respeita a diversidade dos sujeitos educandos, com uma proposta avaliativa diferenciada e uma concepção de formação profissional acolhedora.

Os limites da concepção formativa do PROEF-2 nos direcionam para discussões mais complexas sobre o campo da Educação de Jovens e Adultos. Percebe-se que a atividade formativa docente do projeto ocorre de forma objetiva no cotidiano das atividades escolares. O PROEF-2 estabeleceu uma rotina de trabalhos que proporciona uma formação 
profissional na EJA. Institucionalmente, no entanto, a objetivação do projeto de extensão não é essa.

O PROEF-2 é um projeto de extensão universitária, destinado à iniciação à docência na modalidade de educação de jovens e adultos. Sendo assim, a iniciação de professores é a intencionalidade maior do projeto e não a formação de educadores/as para a EJA. A formação docente na Educação de Jovens e Adultos ocorre, mas não necessariamente de forma primordial. Observa-se, assim, que a objetivação institucional do projeto se torna sua maior limitação, quando avaliamos a intencionalidade de formar educadores/as para a EJA.

A diferenciação mencionada entre iniciação à docência e formação de educadores/as para a EJA pode ser mensurada nas respostas dos monitores professores, quando questionados sobre as motivações que os levaram a ingressar no projeto de extensão. Todos eram inexperientes no exercício da docência e afirmaram que desejavam obter experiência profissional, o que nos leva à configuração institucional do projeto, relacionada a iniciar professores/as na prática de ofício. Nesse sentido, é preciso explicar a distinção aqui dimensionada entre iniciação docente e formação docente específica para a Educação de Jovens e Adultos. Obviamente, a iniciação à docência constitui-se como um processo de formação profissional, no sentido de desenvolver experiências pedagógicas na prática docente. A iniciação à docência, no entanto, pode ocorrer em qualquer modalidade de ensino, visto que o objetivo principal é fomentar a formação inicial de futuros professores. Já a formação específica de educadores/as para uma determinada modalidade requer particularidades nos processos formativos, de acordo com as características e as demandas da modalidade educativa em questão.

Sendo assim, a distinção mencionada entre iniciação docente e formação docente para a EJA no PROEF-2 está relacionada ao estímulo da formação docente intencionada. Dos sete monitores professores entrevistados, apenas uma relatou conhecimentos pregressos sobre a Educação de Jovens e Adultos. Quando questionados a respeito das possibilidades acadêmicas e profissionais futuras na EJA, somente duas professoras monitoras afirmaram efetivamente essa possibilidade. Dessa forma, a maioria dos monitores da equipe de trabalho pesquisada buscou ingresso no projeto em busca de uma experiência profissional docente, independente da modalidade de ensino. Certamente, essa é uma busca legítima e corresponde às pretensões do projeto em formar novos professores. A diferenciação aqui discutida envolve tão somente o entendimento de que há distinções entre a busca por uma formação inicial de professores/as e o estabelecimento de uma formação específica de professores/as para a EJA, ressaltando, é claro, que ambas as formações podem ocorrer em conjunto.

Dessa forma, devem ser pensadas propostas de institucionalização que agreguem contribuições e reduzam as limitações aqui abordadas. Dentre essas limitações, evidencia- 
se um fator bastante mencionado pelos monitores professores relativo ao valor da remuneração recebida a título de bolsa de extensão. Apesar de estarem em formação, os monitores professores assumem responsabilidades de educadores, mas são remunerados como bolsistas. Entende-se que a baixa remuneração dos monitores bolsistas surge com um limitador da experiência formativa, visto que isso pode desmotivar a permanência dos monitores no projeto e contribuir, desde a formação profissional, para o fortalecimento da imagem do professorado como uma classe mal remunerada e de baixo prestígio profissional.

\section{Considerações Finais}

Esta pesquisa compreende que o PROEF-2 constitui-se como um espaço de formação inicial de professores/as, com características e especificidades formativas voltadas para a Educação de Jovens e Adultos. Dessa forma, recordando o objeto central desta investigação, acerca dos limites e das contribuições do PROEF-2 para a formação de educadores/as de jovens e adultos, avalia-se que a experiência docente no PROEF-2 contribui efetivamente para a formação de educadores/as para a EJA e que suas limitações se encontram nas delimitações institucionais inerentes às ações de um projeto de extensão universitária.

O devir do processo investigativo identificou fatores que demonstraram a afinidade das atividades formativas desenvolvidas no projeto com as necessidades $e$ as especificidades da EJA. Ao mesmo tempo, avalia-se que a prática docente vivenciada no projeto igualmente capacite os monitores bolsistas para experiências profissionais futuras, independentemente da modalidade de ensino. Nesse sentido, o PROEF-2 impõe-se, primeiramente, como um ambiente propenso ao desenvolvimento de aprendizagens e de representações relacionadas à formação inicial de profissionais docentes. Um dos pontos que favorecem a proposta de formação docente do projeto de extensão é a capacitação dos profissionais envolvidos na coordenação e na orientação do PROEF-2. Observou-se que as coordenadoras entrevistadas possuem elevado nível de formação acadêmica e grande experiência no ofício docente, além de demonstrarem comprometimento e responsabilidade profissional na formação dos monitores por elas coordenados.

Nesse contexto, o que a experiência formativa docente no PROEF-2 reitera é que se deve sempre optar pelo diálogo nos processos formativos. Propostas de ensino desenvolvidas a partir do compartilhamento democrático de ideias, que respeitem a diversidade de pensamentos, devem ser incentivadas. Obviamente, as propostas pedagógicas construídas nem sempre ocorrerão como planejado, o que não quer dizer que 
elas fracassaram. Muitas delas serão retificadas ou reconstruídas para melhor eficácia. 0 importante é que elas intercorram em um regime democrático de opiniões.

Ao avaliar as contribuições do PROEF-2, na formação de educadores/as de jovens e adultos, constatou-se como fator contributivo de maior relevância a possibilidade real de formação de professores/as para EJA ofertada pelo projeto. O fator de limitação que mais se evidencia é a delimitação institucional estabelecida a um projeto de extensão universitária, na ampliação das atividades escolares e formativas desenvolvidas no projeto. Entende-se, entretanto, que as contribuições descritas superam as limitações observadas e que estas podem ser superadas com planejamentos institucionais futuros, adequados às demandas e às consolidações do PROEF-2.

Por fim, as considerações desta pesquisa avaliam que a formação docente na EJA perpassa pela renovação dos conceitos sobre a atividade educativa cotidiana. A experiência formativa avaliada estimula o desenvolvimento e a reflexão acerca das teorias e das metodologias docentes previamente adquiridas nos cursos de formação, estabelecendo, assim, que a continuidade do aprendizado docente é algo inerente à prática da atividade educacional. É preciso redimensionar e fomentar a construção de processos de formação docentes mais dialógicos e estruturados às realidades dos educandos. Dessa forma, as proposições almejadas para formação de educadores/as de jovens e adultos precisam proporcionar descobertas, não somente pedagógicas, mas igualmente de caráter vocacional.

Espera-se que este estudo tenha se configurado positivamente diante das questões que envolvem a Educação de Jovens e Adultos como uma modalidade de ensino preponderante, em especial na temática da formação de educadores/as. Novas averiguações são necessárias, para que outros questionamentos sejam abordados e outras reflexões sejam feitas. Em meio a esses questionamentos e reflexões, uma questão se sobressai: a necessidade de diálogo democrático nas formas de argumentar, de refletir e de formar novos professores/as.

\section{Referências}

BORGHI, I. S. M. Formação de educadores da EJA: inquietações e perspectivas. In: Revista Diálogos Possíveis. Ano 6, v. 2, p. 227-238, jul./dez. 2007.

DINIZ-PEREIRA, J. E.; FONSECA, M. C. F. R. Identidade docente e formação de Educadores de Jovens e Adultos. In: Rev. Educação e Realidade, Porto Alegre, v. 26, n.2, p. 51-73, 2001.

FREIRE, P. Pedagogia da Autonomia: saberes necessários a prática educativa. 26aㅗ ed. São Paulo: Editora Paz e Terra, 1996. 
FREIRE, P. Pedagogia do Oprimido. 11를 Ed. Rio de Janeiro: Editora Paz e Terra, 1970.

MIRANDA, K. C. L.; BARROSO, M. G. T. A contribuição de Paulo Freire à prática e educação crítica em enfermagem. Rev. Latino-Am. Enfermagem, Ribeirão Preto, v. 12, n. 4, p. 631-635, Ago. 2004.

NÓVOA. A. Formação de Professores e Profissão Docente. FPDC-UOE-HEEC, Faculdade de Lisboa. Lisboa, 2007.

RIBAS, M. S.; SOARES, S. T. Formação de Professores para atuar na Educação de Jovens e Adultos: uma reflexão para o desenvolvimento e aperfeiçoamento da prática docente. In: Anais do IX Seminário de Pesquisa em Educação da Região Sul - ANPED SUL. Caxias do Sul - RS: Universidade de Caxias do Sul, 2012, p. 01-16.

SILVA, F. A. O. R. Elementos para a construção das especificidades na formação do educador da EJA. 2013. 372f. Tese (Doutorado em Educação) - Faculdade de Educação, Universidade Federal de Minas Gerais, 2011.

SOARES, L. A Formação do Educador de Jovens e Adultos. In: SOARES, L. (Org.). Aprendendo com a Diferença - Estudos e Pesquisas em Educação de Jovens e Adultos. Belo Horizonte: Editora Autêntica, 2003, p. 121- 141.

SOARES, L. A Formação de Educadores e as Especificidades da Educação de Jovens e Adultos em Propostas de EJA. In: Anais do V Seminário Nacional sobre Formação de Educadores de Jovens e Adultos. Campinas - SP: UNICAMP, 2015.

SOARES, L. O educador de jovens e adultos e sua formação. Educ. Rev., Belo Horizonte , n. 47, p. 83-100, Jun. 2008.

TARDIF, M. Saberes Decorrentes e Formação Profissional. Petrópolis - RJ: Ed. Vozes, 2002.

VENTURA, J. A EJA e os Desafios da formação Docente nas Licenciaturas. Educação e Contemporaneidade, Salvador, v. 21, n. 37, p. 71-82, jan./jun. 2012. 